\title{
Expression of Transferrin and Albumin in the Sperm-Storage Tubules of Japanese Quail and their Possible Involvement in Long-Term Sperm Storage
}

\author{
Mei Matsuzaki ${ }^{1,2}$, Shusei Mizushima ${ }^{3}$, Hideo Dohra ${ }^{4}$ and Tomohiro Sasanami ${ }^{1}$ \\ ${ }^{1}$ Department of Applied Life Sciences, Faculty of Agriculture, Shizuoka University, \\ 836 Ohya, Shizuoka, Shizuoka 422-8529, Japan \\ ${ }^{2}$ Program of Food and AgriLife Science, Graduate School of Integrated Sciences for Life, Hiroshima University, \\ 1-4-4 Kagamiyama, Higashi-Hiroshima City, Hiroshima 739-8528, Japan \\ ${ }^{3}$ Department of Biological Sciences, Faculty of Science, Hokkaido University, \\ Kita 10 Nishi 8, Kita-ku, Sapporo, Hokkaido 060-0810, Japan \\ ${ }^{4}$ Research Institute of Green Science and Technology, Shizuoka University, \\ 836 Ohya, Shizuoka, Shizuoka 422-8529, Japan
}

\begin{abstract}
Because of the presence of sperm storage tubules (SSTs) in the utero-vaginal junction (UVJ) in the oviduct, once ejaculated sperm enter the female reproductive tract, they can survive for a prolonged period in domestic birds; however, the specific mechanisms involved in sperm maintenance within the SST remain to be elucidated. In this study, we showed that transferrin (TF) and albumin (ALB) are expressed in SSTs. When UVJ extracts were subjected to size-exclusion column chromatography, we obtained fractions that extend sperm longevity in vitro. LC-MS/MS analysis of the two major proteins in the fractions identified these proteins as TF and ALB. Immunohistochemical analysis using specific antisera against TF and ALB indicated that both proteins were localized not only in the SSTs, but also in the surface epithelium of the UVJ. When the ejaculated sperm were incubated with either purified TF or ALB, sperm viability increased after $24 \mathrm{~h}$. These results indicated that oviductal TF and ALB are involved in the process of sperm storage in SSTs and may open a new approach for technological improvement to prolong sperm longevity in vitro.
\end{abstract}

Key words: albumin, Japanese quail, sperm longevity, sperm storage tubules, transferrin

J. Poult. Sci., 57: 88-96, 2020

\section{Introduction}

A striking feature of avian reproduction is long-term sperm storage in sperm storage tubules (SSTs) located in the utero-vaginal junction (UVJ) of the oviduct (Bobr et al., 1964). Spermatozoa ejaculated into the female vagina migrate into the SSTs within one hour of insemination (Das et $a l ., 2006)$. They are then stored for extended periods and retain their fertilizability at normal body temperature (i.e.,

Received: April 19, 2019, Accepted: May 28, 2019

Released Online Advance Publication: June 25, 2019

Correspondence: Tomohiro Sasanami, Department of Applied Life Sciences, Faculty of Agriculture, Shizuoka University, 836 Ohya, Shizuoka, Shizuoka 422-8529, Japan. (E-mail: atsasan@shizuoka.ac.jp)

The Journal of Poultry Science is an Open Access journal distributed under the Creative Commons Attribution-NonCommercial-ShareAlike 4.0 International License. To view the details of this license, please visit (https:// creativecommons.org/licenses/by-nc-sa/4.0/). $41.5^{\circ} \mathrm{C}$ ) (Birkhead and Møller, 1992). Because spermatozoa are terminally differentiated cells and cannot produce new protein after ejaculation, the mechanism by which sperm longevity can be maintained for long periods is a longstanding enigma. Elucidating this mechanism is of interest to scientists in the field of poultry science since the mechanism of sperm maintenance within SSTs is directly linked to the development of a novel strategy for long-term sperm preservation in vitro.

Huang et al. (2016) reported that SSTs in the hen oviduct expressed lipases and lipid receptors through which SST cells could degrade lipids to release fatty acids into the lumen. Although the effects were limited, the addition of oleic acid or linoleic acid into the incubation mixture significantly improved sperm viability after $24 \mathrm{~h}$ of incubation, indicating the involvement of fatty acids in sperm survival. Several proteins, including carbonic anhydrase (Holm et al., 1996), avidin (Foye-Jackson et al., 2011), aquaporins 
(Zaniboni and Bakst, 2004), and alkaline phosphatase (Bakst and Akuffo, 2007), have been suggested to have potential roles in sperm maintenance in SSTs, although the physiological importance is not clear. Another important factor supporting sperm viability in SSTs is the protection of resident sperm from antisperm immune responses. Das et al. (2006) demonstrated that the elimination of antisperm immune responses by transforming growth factor beta (TGFB) is one of the factors responsible for sperm maintenance in SSTs. Therefore, the sperm maintenance system in SSTs appears to consist of multiple events acting together to achieve longterm sperm survival for successful fertilization.

In our previous study, we demonstrated that one of the most important physiological phenomena for sperm maintenance in SSTs is a hypoxic environment, under which mitochondrial respiration is dramatically inhibited in SSTs (Matsuzaki et al., 2015). Under such a condition, enhanced glycolysis in SST cells leads to the accumulation of a large quantity of L-lactic acid in the lumen of SSTs and resident sperm exposed to acidic conditions become immotile due to the inhibition of flagellar dynein ATPase, the motor protein required for sperm flagellar movement (Matsuzaki et al., 2015). However, such a condition alone appears to be insufficient to maintain sperm fertilizability in vitro because we found that sperm viability was lost within $24 \mathrm{~h}$ of incubation in the presence of L-lactic acid. Alternatively, the incompetency of L-lactic acid for long-term sperm maintenance in vitro clearly suggests that additional mechanisms operate in the process of sperm storage in SSTs, and further studies are required to develop novel strategies for sperm preservation in vitro.

In this study, we aimed to identify additional factors responsible for sperm maintenance in the SSTs of Japanese quail (Coturnix japonica). Using biochemical and immunohistochemical analysis, we report the expression and presence of albumin (ALB) and transferrin (TF) in the UVJ. Moreover, the possible involvement of these proteins in sperm maintenance was tested by in vitro incubation of ejaculates with these proteins.

\section{Materials and Methods}

\section{Animals and Tissue Preparation}

Eight- to twenty-week-old male and female Japanese quails (Quail Cosmos, Tahara, Japan) were maintained individually under a 14:10 h light: dark photoperiod (lights went on at 05:00) and had ad libitum access to water and a commercial diet (Toyohashi Feed Mills, Toyohashi, Japan).

The UVJ mucosa was dissected out and placed in physiological saline. The UVJ mucus membranes containing SSTs were isolated with forceps and scissors under a stereomicroscope (M165 FC; Leica Microsystems, Tokyo, Japan) according to the method of Ito et al. (2011). Excised UVJ tissues were minced in ice-cold PBS ( $1 \mathrm{~g}$ wet tissue in $2 \mathrm{~mL}$ of buffer) and extracted for $3 \mathrm{~h}$ on ice with occasional shaking. The extracts were centrifuged at $20000 \times g$ for $10 \mathrm{~min}$ at $4^{\circ} \mathrm{C}$, and the supernatants were used as UVJ extracts.

A portion between the uterus and the vagina was opened longitudinally, and $50 \mu \mathrm{L}$ of PBS was dropped onto the UVJ mucosal surface. The solution containing oviductal fluid in the UVJ was collected using a pipette, and this was repeated three times. The collected solution $(150 \mu \mathrm{L}$ in total) was centrifuged at $20000 \times g$ for $5 \mathrm{~min}$ at $4^{\circ} \mathrm{C}$, and the supernatant was stored at $-80^{\circ} \mathrm{C}$.

Semen was obtained from male quails during mating prior to ejaculation according to the procedure of Kuroki and Mori (1997). Semen obtained from two or three males was suspended in Hanks' balanced salt solution (HBSS: Thermo Fisher Scientific K. K., Yokohama, Japan) supplemented with $1.26 \mathrm{mM} \mathrm{CaCl}_{2}, 0.8 \mathrm{mM} \mathrm{MgSO}_{4}$, and $4.2 \mathrm{mM} \mathrm{NaHCO}_{3}$. The sperm concentrations were measured with a hemocytometer and the sperm were incubated at $39^{\circ} \mathrm{C}$ in all experiments. All procedures for the care and experimental use of animals were carried out in accordance with the approved guidelines of the Animal Care Committees of Shizuoka University (Approval number: 2018A-5).

\section{Assays for Sperm Motility and Viability}

Sperm motility was evaluated by directly observing sperm in several areas of a petri dish under a stereomicroscope, and motility qualitative scores were assigned using an arbitrary grading system from 0 to 4 , with a score of 0 indicating no movement; 1 indicating tail movement, but not sperm progression; 2 indicating that a large percentage of spermatozoa showed progressive, but not rectilinear, movement; 3 indicating that a large percentage of spermatozoa showed rectilinear, but not vigorous, movement; and 4 indicating that a large percentage of spermatozoa showed vigorous rectilinear movement (Wheeler and Andrews, 1943).

Sperm viability was assessed using a LIVE/DEAD sperm viability kit according to the manufacturer's instructions (Molecular Probes, Thermo Fisher Scientific K. K.).

\section{Gel-filtration Chromatography and Ion-exchange Chroma- tography}

The UVJ extracts were centrifuged at $20000 \times g$ for $10 \mathrm{~min}$ at $4^{\circ} \mathrm{C}$ and the supernatants were filtered through a $0.45-\mu \mathrm{m}$ membrane filter unit (Millipore, Merck Japan, Tokyo, Japan). The filtrates were separated on a Sephacryl $200 \mathrm{HR}$ column (GE Healthcare Japan, Hino, Japan) according to our previous methods (Matsuzaki et al., 2015).

To isolate ALB and TF, UVJ extracts were subjected to ultrafiltration through a $>10 \mathrm{kDa}$-cutoff membrane (Centricon; Millipore, Merck), and the concentrates were centrifuged at $20000 \times g$ for $10 \mathrm{~min}$ at $4^{\circ} \mathrm{C}$. The supernatants were filtered through a $0.45-\mu \mathrm{m}$ membrane (Millipore, Merck). The filtrates were subjected to separation on a BioScale Mini Macro-Prep DEAE cartridge $(5 \mathrm{~mL}$, Bio-Rad, CA, USA) pre-equilibrated with $25 \mathrm{mmol} / \mathrm{L}$ Tris- $\mathrm{HCl}(\mathrm{pH}$ 8.0). The column was first eluted with $25 \mathrm{mmol} / \mathrm{L}$ Tris- $\mathrm{HCl}$ (pH 8.0) for $20 \mathrm{~min}$, and then eluted with a linear gradient of 0 to $0.5 \mathrm{~mol} / \mathrm{L} \mathrm{NaCl}$ in $25 \mathrm{~mol} / \mathrm{L}$ Tris- $\mathrm{HCl}(\mathrm{pH} 8.0)$ at a flow rate of $2 \mathrm{~mL} / \mathrm{min}$ for $140 \mathrm{~min}$.

\section{LC-tandem Mass Spectrometry (LC-MS/MS) Analysis}

An SDS-PAGE gel strip containing a bioactive fraction was stained with Coomassie brilliant blue (CBB). A piece of gel $\left(1 \mathrm{~mm}^{2}\right)$ containing the first and second major bands 
(approximately $75 \mathrm{kDa}$ and $65 \mathrm{kDa}$, respectively) was excised. The proteins in the gel were processed for in-gel digestion using sequence-grade trypsin as suggested by the manufacturer (Promega K. K. Tokyo, Japan). The peptides recovered from the gel were analyzed by tandem mass spectrometry (MS/MS; NanoFrontier eLD; Hitachi HighTechnologies Corporation, Tokyo, Japan) according to the manufacturer's instructions. To identify the proteins obtained from the MS/MS analysis, a de novo sequencing software package, PEAKS, was used as previously described (Ma et al., 2003). To confirm the reliability of the de novo sequencing data, we used two other proprietary identification programs, Mascot (http://www.matrixscience.com/) and SPIDER (http://www.bioinfor.com/products/peaks/spider. php), as previously described (Perkins et al., 1999).

RT-PCR

Total RNA was isolated from the dissected tissue samples using RNAiso (Takara Biomedical, Otsu, Japan) according to the manufacturer's instructions. Aliquots $(0.5 \mathrm{mg})$ were reverse transcribed at $37^{\circ} \mathrm{C}$ for $15 \mathrm{~min}$ using a ReverTra Ace qPCR kit (Toyobo, Osaka, Japan). PCR amplification was performed using primer sets specific for $T F$ (sense: $5^{\prime}$ AAGGAGACGTGGCTTTTGTG - $3^{\prime}$; antisense, 5' GAAGAGCAAGTGTGACCGCT - $3^{\prime}$ ) and $A L B$ (sense: $5^{\prime}$ GGACATGGTGGAGTGCATGG - $3^{\prime}$; antisense, $5^{\prime}$ CTGTATGGAGAACTCAGGGTGTC - $3^{\prime}$ ). For the nonreverse transcribed control, total RNA was treated in the same way except that reverse transcriptase was replaced with water. The products were analyzed on a $1 \%$ agarose gel stained with ethidium bromide and visualized using ImageQuant LAS 500 (GE Healthcare, Japan).

\section{Antisera}

Rabbit polyclonal anti-TF and anti-ALB antisera were raised against commercially available bovine serum TF or chicken serum ALB (Sigma-Aldrich Japan, Tokyo, Japan). A single female New Zealand White rabbit (Japan SLC, Inc., Hamamatsu, Japan) was immunized with the protein as described previously (Kuroki and Mori, 1997). Briefly, the rabbit was injected subcutaneously at multiple sites along the back with $1 \mathrm{~mL}$ of an emulsion prepared by mixing equal volumes of Freund's complete adjuvant (Sigma-Aldrich) and transferrin or albumin $(300 \mu \mathrm{g} / \mathrm{mL})$. Booster injections with the same concentration of antigen in Freund's incomplete adjuvant (Sigma-Aldrich) were administered six and eight weeks after the first immunization. Blood was collected two weeks after the final injection, and serum aliquots were stored at $4^{\circ} \mathrm{C}$.

\section{SDS-polyacrylamide Gel Electrophoresis (SDS-PAGE) and Western Blotting}

SDS-PAGE was carried out under reducing conditions as described previously (Laemmli, 1970), using 12\% (w/v) and $5 \%(\mathrm{w} / \mathrm{v})$ polyacrylamide for the resolving and stacking gels, respectively. For western blotting, proteins from the UVJ extracts or oviductal fluid separated by SDS-PAGE were transferred onto a PVDF membrane (Immobilon-P; Millipore, Merck) (Matsudaira, 1987). The membrane was then incubated with blocking buffer containing $5 \%(\mathrm{w} / \mathrm{v})$ skim- med milk in PBS supplemented with $0.1 \%$ (w/v) Tween 20 for $30 \mathrm{~min}$. The membrane was allowed to react with the antisera, or antisera preincubated with antigen proteins diluted with blocking buffer (both 1:10,000), and visualized using HRP-conjugated anti-rabbit IgG (Cappel, Durham, NC, USA) and Luminata Forte western HRP substrate (Millipore, Merck). Chemiluminescence was detected using an ImageQuant LAS 500 (GE Healthcare, Japan).

\section{Immunohistochemistry}

The UVJ mucosa was fixed in Bouin's fixative and embedded in Paraplast (Oxford Labware, MO, USA). Sections $(4 \mu \mathrm{m}$ thick) were air-dried and then incubated with ethanol containing $1 \% \mathrm{H}_{2} \mathrm{O}_{2}$ for 20 min to inactivate endogenous peroxidases after deparaffinization. After washing with PBS, the sections were blocked with PBS containing $1 \%$ BSA and $10 \%$ normal goat serum for $1 \mathrm{~h}$. The immunohistochemical techniques used were as described previously (Sasanami et al., 2002). Anti-TF antiserum (1:100), anti-TF antiserum preincubated with antigen proteins $(1: 100)$, antiALB antiserum (1:100), anti-ALB antiserum preincubated with antigen proteins (1:100), and HRP-conjugated goat antirabbit IgG (Cappel, MP Bio Japan, Tokyo, Japan) were used. The samples were lightly stained with hematoxylin. The immunolabeled sections were examined under a light microscope (BX51; Olympus Optics, Tokyo, Japan) using a Nomarski filter.

\section{Statistical Analysis}

Data are expressed as means \pm S.D. and were analyzed by ANOVA for significant differences. Means were compared using Tukey's test. For percentage data, an arcsine squareroot transformation was performed, and the transformed data were compared using the Student's t-test. The MannWhitney $U$ test was used to compare group motility scores. Differences were considered statistically significant when $P$ $<0.05$.

\section{Results}

\section{Identification of Factors Affecting Sperm Longevity in UVJ Extracts}

To identify the bioactive components responsible for sperm maintenance in SSTs, UVJ extracts were fractionated by gel filtration chromatography and pooled fractions were tested for sperm viability after $24 \mathrm{~h}$ of incubation. As shown in Fig. 1, fractions $30^{-45}$ and $60^{-75}$ maintained higher sperm motility than the control (Fig. 1b). In our previous study, we demonstrated that fractions equivalent to fractions $60-75$, with the same preparation, contained L-lactic acid and that this substance also had a potent effect in maintaining sperm motility (Matsuzaki et al., 2015); therefore, we focused on fractions $30^{-45}$ in the current study. SDS-PAGE and subsequent gel staining revealed that this fraction contained a $75 \mathrm{kDa}$ protein (protein 1) and a $65 \mathrm{kDa}$ protein (protein 2). We then performed an LC-MS/MS analysis to identify these proteins and found that proteins 1 and 2 were serotransferrin and serum albumin, respectively, with a coverage score greater than $50 \%$ (Table 1). 

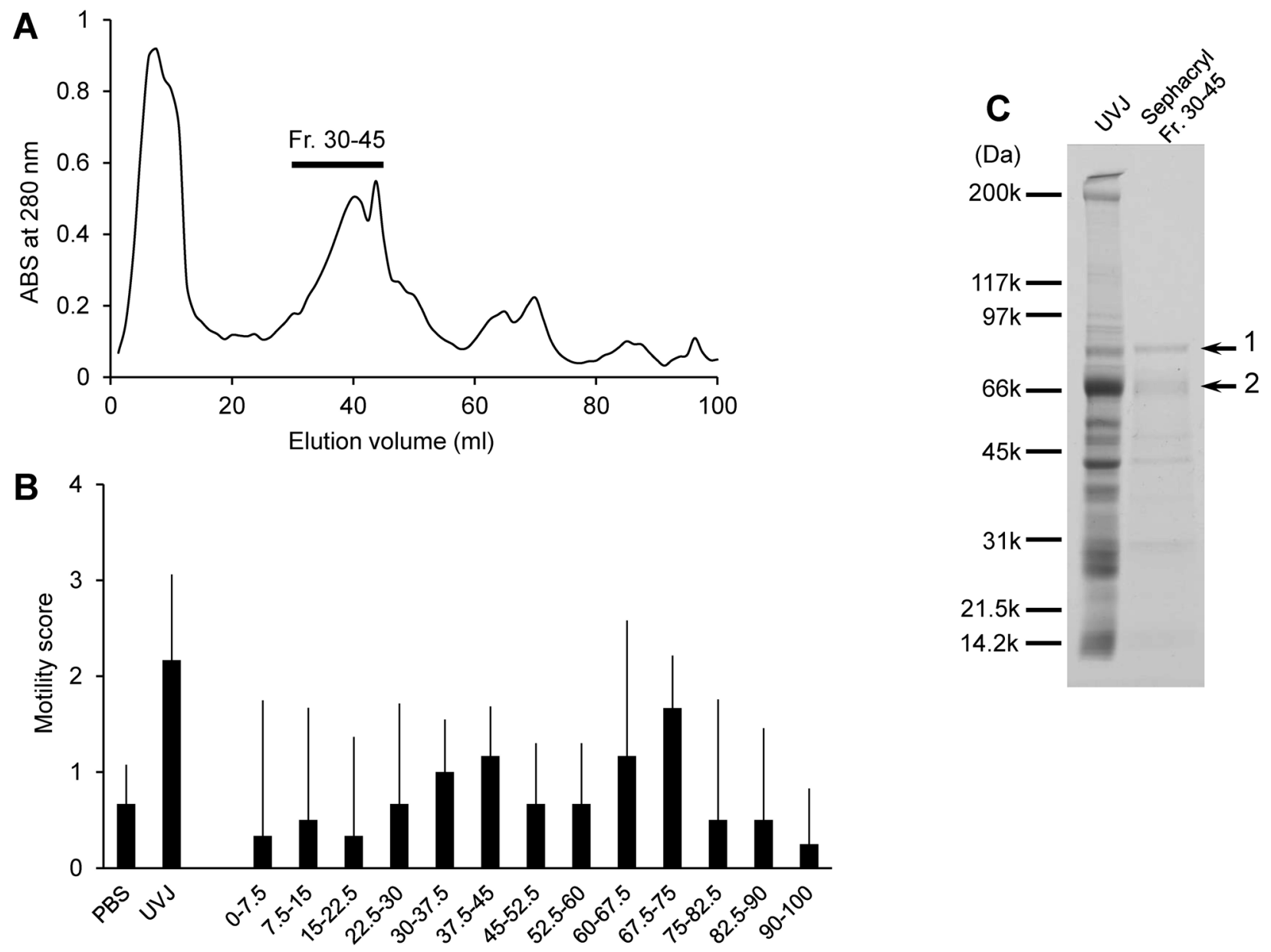

Fig. 1. Separation of active components that extend sperm longevity by size exclusion chromatography. (a) Utero-vaginal junction (UVJ) extracts were loaded onto a Sephacryl 200 HR column. Detectable peaks were observed and each

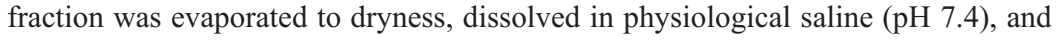
applied in a sperm motility assay. The bioactive fraction is indicated by the horizontal bar. (b) Effects of chromatography fractions on sperm motility. Ejaculated sperm were suspended in medium containing each fraction $(1 \%[\mathrm{v} / \mathrm{v}])$ and the effects of each fraction on sperm motility were evaluated. Bioactivity was detected in fractions 30-45. Data are expressed as the mean \pm SD of 6 trials for PBS, UVJ, and fractions $0-75$; and 4 trials for fractions 75-100. (c) SDS-PAGE analysis of the bioactive substances. A mixture of fractions 30 to 45 (in panel b) was separated by SDS-PAGE, and the gel was detected using Coomassie brilliant blue (CBB). Arrows indicate the two major bands detected.

\section{Expression and Localization of Transferrin and Albumin}

In the next set of experiments, we analyzed $A L B$ and $T F$ gene expression in the UVJ mucosa by RT-PCR. As shown in Figures 2a and 3a, both $T F$ and $A L B$ were expressed in the UVJ mucosa (lane + ). Next, we prepared antisera against TF (anti-TF) and ALB (anti-ALB) and investigated the localization of these proteins in the UVJ. Western blot analysis indicated that anti-TF and anti-ALB reacted well with bands that migrated around 75 and $65 \mathrm{kDa}$, respectively (Fig. $2 \mathrm{~b}$ and $2 \mathrm{c}$; lane - ). These bands disappeared when the antisera were neutralized with the respective antigens (Fig.
$2 \mathrm{~b}$ and $2 \mathrm{c}$; lane + ), indicating the specificity of our antibodies. To reveal the localization of TF and ALB in the UVJ, we subsequently performed immunohistochemistry. As shown in Figures 2c and 3c, DAB-positive immunoreactivity was observed in both the UVJ and SST epithelial cells, but not with antisera neutralized with the respective antigens (Figs $2 \mathrm{~d}$ and $3 \mathrm{~d}$ ). Notably, a scattered expression pattern was observed in both surface epithelial cells and SST cells, although not in all the cells. We further investigated whether $\mathrm{TF}$ and ALB were released into the oviductal lumen. When an oviductal flush was probed by western blot, immunoreac- 
Table 1. Summary of tandem mass spectrometry analysis

\begin{tabular}{ccccccc}
\hline \hline $\begin{array}{c}\text { Sample } \\
\text { no. }\end{array}$ & Accession & $-10 \operatorname{lgP}$ & $\begin{array}{c}\text { Coverage } \\
(\%)\end{array}$ & \#Peptides & Avg. Mass & Description \\
\hline 1 & XP_015726719.1 & 240.04 & 53 & 36 & 77625 & PREDICTED: serotransferrin [Coturnix japonica] \\
2 & XP_015717009.1 & 204.97 & 53 & 30 & 69842 & PREDICTED: serum albumin [Coturnix japonica] \\
\hline
\end{tabular}
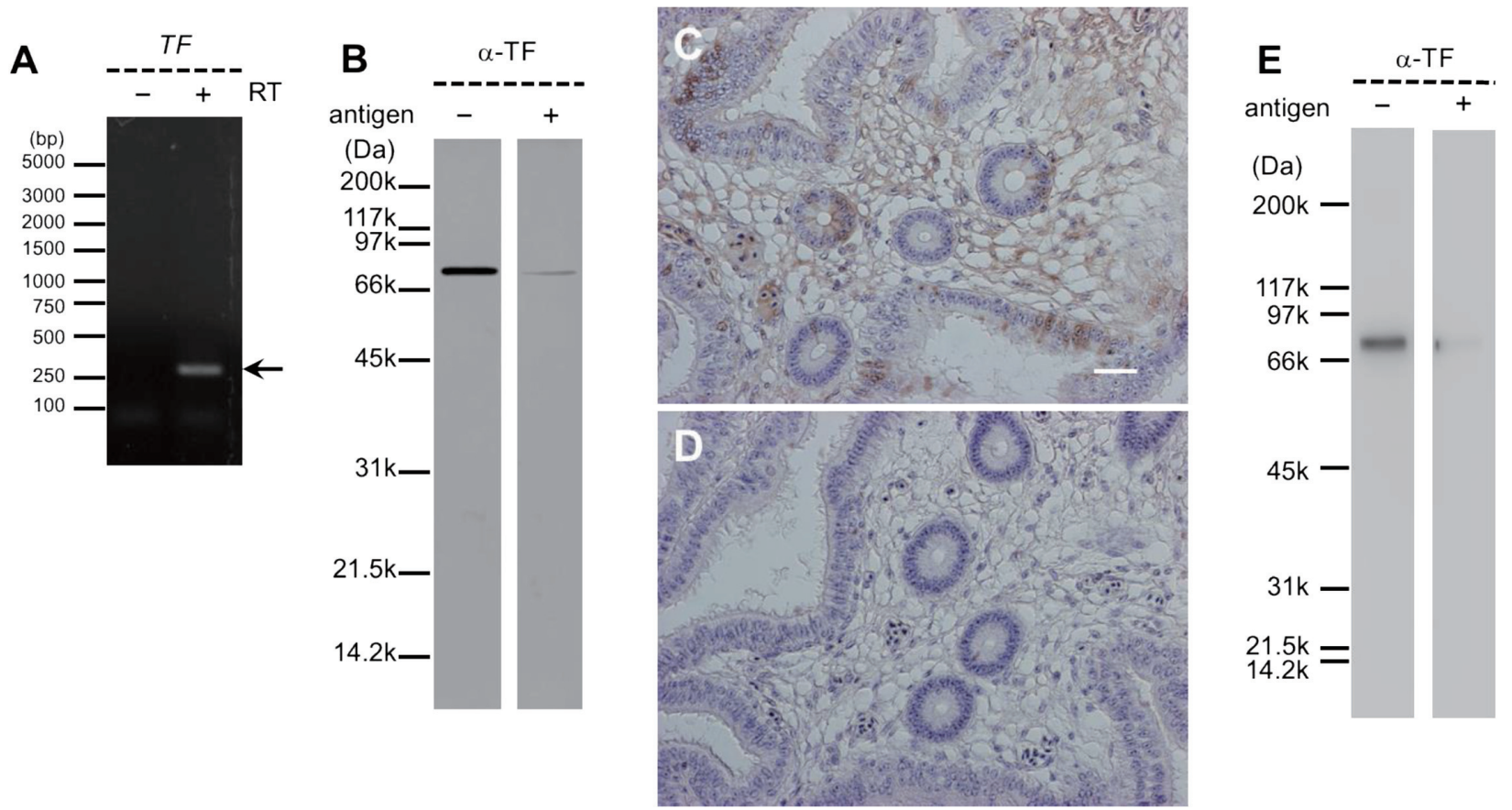

Fig. 2. Expression of transferrin in the utero-vaginal junction (UVJ). (a) Gene expression of transferrin $(T F)$ in the UVJ. The mRNA extracted from the UVJ was reverse transcribed and an aliquot was subjected to PCR using a $T F$ specific primer set (lane + ). As a non-reverse transcribed control, mRNA from the UVJ was treated the same way, except that reverse transcriptase (lane -) was omitted. A representative gel of three independent experiments is shown. (b) The UVJ extracts $(0.1 \mu \mathrm{g}$ protein/lane) were separated by SDS-PAGE under reducing conditions, transblotted onto PVDF membranes, and detected with anti-TF antiserum (lane -, 1:10,000) or anti-TF antiserum preabsorbed with antigen protein (lane $+, 1: 10,000)$. Immunohistochemical observations using anti-TF antiserum (c) or anti-TF antiserum preabsorbed with antigen protein (d). Nuclei were counterstained with hematoxylin. Representative results of three experiments are shown. Bar $=50 \mu \mathrm{m}$. (e) An oviductal flush was prepared and $0.1 \mu \mathrm{g}$ protein/lane was detected with anti-TF antiserum (lane $-, 1: 10,000)$ or anti-TF antiserum preabsorbed with antigen protein (lane $+, 1: 10,000)$.

tive TF and ALB were both detected. Again, no such signals were detected when the blot was detected with neutralized antisera (Figs 2e and 3e).

\section{Effects of Transferrin and Albumin on Sperm Viability}

To evaluate the effect of TF and ALB on sperm viability, we purified these proteins from the UVJ extracts. The UVJ extracts were separated using a DEAE column (Fig. 4a); western blot analysis using specific antisera demonstrated that fractions 9-11 and 15-17 contained TF and ALB, respectively (Fig. 4b and 4c). The effects of the purified pro- teins on sperm viability were then tested (Fig. 5). Incubating ejaculates with $25 \mu \mathrm{g} / \mathrm{mL}$ purified $\mathrm{TF}$ increased sperm viability at $24 \mathrm{~h}$ of incubation (panel a). Although the reasons are not known, adding $100 \mu \mathrm{g} / \mathrm{mL}$ TF tended to decrease sperm viability. However, the regression line of TF concentration and sperm viability showed a statistically significant correlation. Purified ALB had similar effects, although at much higher doses than for $\mathrm{TF}$, in maintaining sperm viability (panel b). 

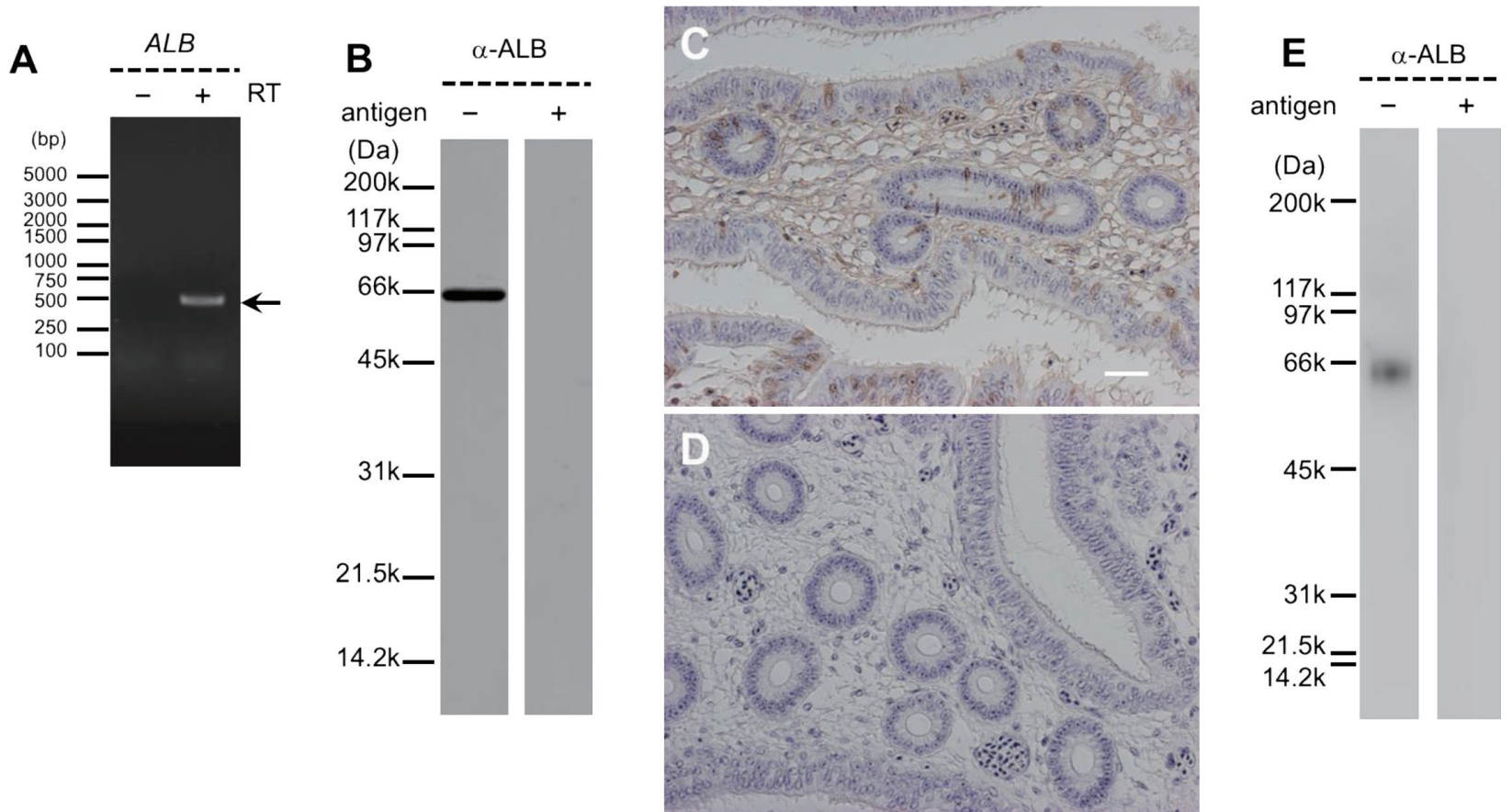

Fig. 3. Expression of albumin (ALB) in the utero-vaginal junction (UVJ). (a) Gene expression of $A L B$ in the UVJ. The mRNA extracted from the UVJ was reverse transcribed, and an aliquot was subjected to PCR using an $A L B$-specific primer set (lane + ). As a non-reverse transcribed control, mRNA from the UVJ was treated the same way, except that reverse transcriptase (lane -) was omitted. A representative gel of three independent experiments is shown. (b) The UVJ extracts $(0.1 \mu \mathrm{g}$ protein/lane) were separated by SDS-PAGE under reducing conditions, transblotted onto PVDF membranes, and detected with anti-ALB antiserum (lane -, $1: 10,000)$ or anti-ALB antiserum preabsorbed with antigen protein (lane,+ 1 : $10,000)$. Immunohistochemical observations using anti-ALB antiserum (c) or antiALB antiserum preabsorbed with antigen protein (d). Nuclei were counterstained with hematoxylin. Representative results of three experiments are shown. Bar $=50$ $\mu \mathrm{m}$. (e) An oviductal flush was prepared and $0.1 \mu \mathrm{g}$ protein/lane was detected with anti-ALB antiserum (lane -, 1:10,000) or anti-ALB antiserum preabsorbed with antigen protein (lane $+, 1: 10,000)$.

\section{Discussion}

In this study, we showed that ALB and TF are expressed in the UVJ of laying quails at both the mRNA and protein levels. To our knowledge, this is the first report on the presence of ALB and TF in the UVJ and on their function in reproductive physiology. ALB and TF are both abundant blood plasma proteins in animals and are mainly produced in the liver (Kuscuoglu et al., 2018). It is known that blood ALB is one of the most abundant proteins, and a major function of ALB is to control oncotic pressure (Fanali et al., 2012). In contrast, TF is reported to be an iron-binding protein that regulates free iron levels in biological fluid in the body (Ganz, 2018). Although the major roles of these proteins are not related to reproduction, we found that they could markedly extend sperm longevity in vitro. In humans, serum ALB has been reported to display antioxidant properties due to its capacity to bind multiple ligands, including free radicals (Roche et al., 2008). Similarly, ovotransferrin, an egg-expressed TF with a global structure identical to that of serotransferrin but differing in the nature of its attached oligosaccharide chain, also exhibits antioxidant properties (Ibrahim et al., 2006). Sperm are typically immotile in the lumen of SSTs (Bakst, 1987), and this inactivation is favorable for long-term sperm survival as it leads to reduced production of reactive oxygen species (ROS) resulting from sperm respiration. We previously found that the $\mathrm{pH}$ of the SST luminal environment is acidic due to the accumulation of lactic acid under hypoxic conditions, and that this environment inactivates sperm motility in the quail SST (Matsuzaki et al., 2015). Therefore, we think that sperm motility inactivation in the SST resulting from luminal acidification may minimize ROS production, and that antioxidant proteins such as ALB and TF expressed in the SST may neutralize ROS for long-term sperm maintenance. Elucidation of the effects of TF and ALB on sperm longevity 

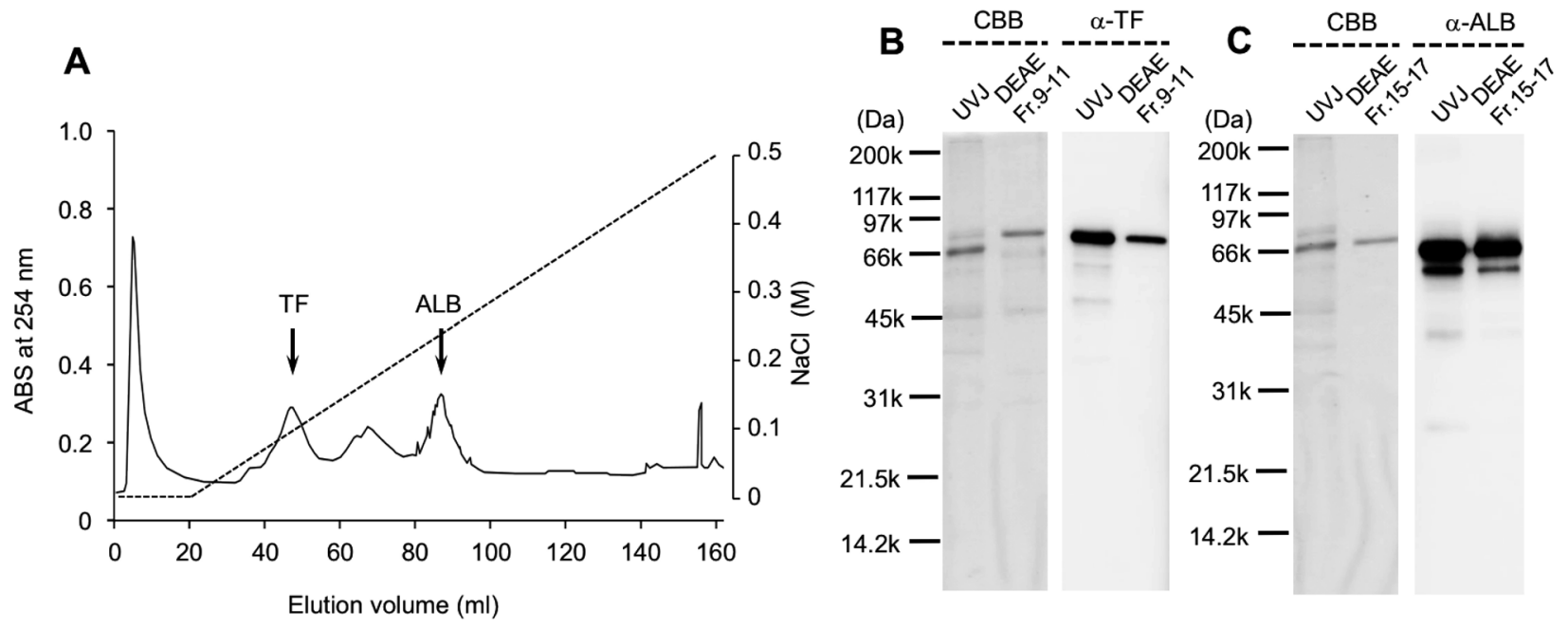

Fig. 4. Purification of transferrin and albumin by anion-exchange chromatography. (a) Chromatographic profile of the utero-vaginal junction (UVJ) extract. $\mathrm{TF}$ and ALB were eluted for approximately $50 \mathrm{~min}$ (fractions 9-11) and $90 \mathrm{~min}$ (fractions 15-17), respectively. (b) UVJ extracts and fraction 9-11 were separated by SDS-PAGE and detected with Coomassie brilliant blue (CBB) or western blotting using anti-TF antiserum. (c) UVJ extracts and fraction 15-17 were separated by SDS-PAGE and detected with $\mathrm{CBB}$ or western blotting using anti-ALB antiserum.
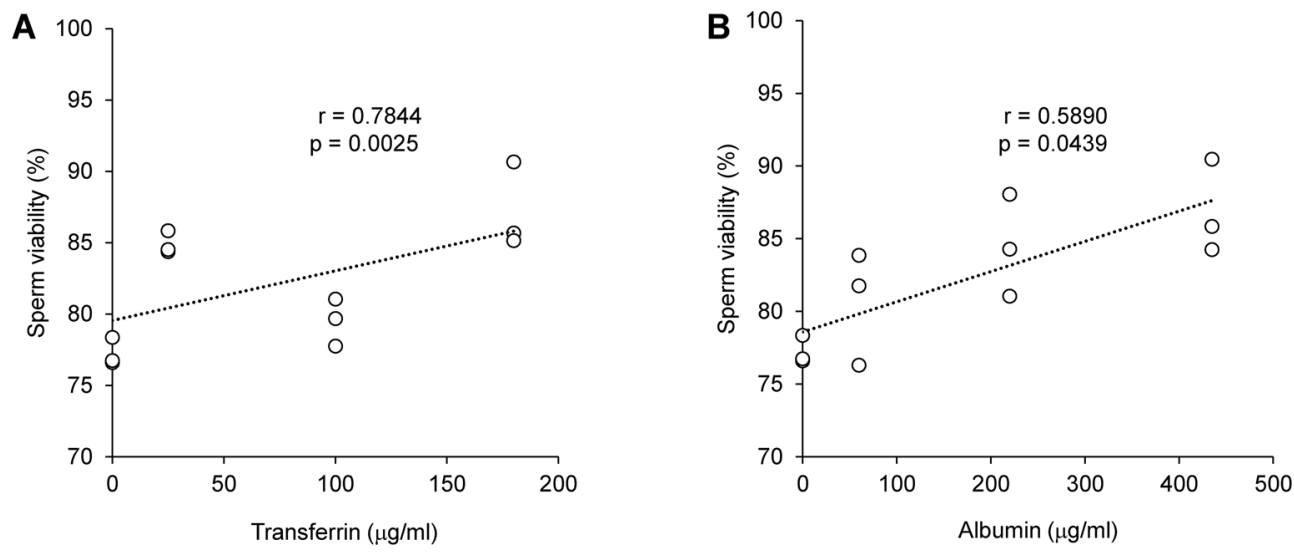

Fig. 5. Effects of transferrin (TF) and albumin (ALB) on the longevity of ejaculated sperm. Ejaculated sperm were suspended in HBSS supplemented with various concentrations of (a) purified TF $(0,25,100$, and $175 \mu \mathrm{g} / \mathrm{mL})$ or (b) purified ALB $(0,50,225$, or $450 \mu \mathrm{g} / \mathrm{mL})$ and incubated for $24 \mathrm{~h}$ at $4^{\circ} \mathrm{C}$. After $24 \mathrm{~h}$ of incubation, a sperm viability assay was performed. Data shown are for three independent experiments. The number of sperm counted per plot ranged from 758 to 1,432 .

under environments similar to that of the lumen of the SST (i.e., the presence of L-lactic acid) remains to be investigated. Ultrastructural observations in turkey SSTs revealed the presence of membrane fragments and small vesicles in the lumen of the SSTs, some of which appeared to have fused with the plasma membrane of resident sperm (Bakst and Bauchan, 2015). In our previous ultrastructural study using quail, we observed secretory granules in SST cells (Ito et al., 2011). Such secretory activities of SST cells also likely contribute to prolonged sperm storage, although we did not confirm if these vesicle/secretory granules contained ALB or TF.

In our study, relatively high concentrations of both ALB and TF were required to elicit sperm maintenance activity 
(i.e., approximately $100-400 \mu \mathrm{g} / \mathrm{mL}$ ). Because serum levels of both ALB and TF are very high (Kuscuoglu et al., 2018; $35-50 \mathrm{mg} / \mathrm{mL}$ and $2.1-3.6 \mathrm{mg} / \mathrm{mL}$ for ALB and TF, respectively), we selected the maximum levels of ALB and TF obtained from ion-exchange chromatography for the assay. Even under such conditions, we found considerable variation in sperm viability (Fig. 5). Although we do not know the actual concentration of these proteins in the oviduct, it would be useful to test the effects on sperm longevity of concentrations of these proteins equivalent to those observed in serum. This may contribute to minimizing experimental variation, although it may be difficult to achieve due to sample limitations. As mentioned above, ALB and TF interact strongly with multiple ligands, including small molecules, and active substances capable of extending sperm longevity may be unknown small ligand molecules on the proteins, but not on the protein/oligosaccharide structures of ALB or TF themselves. Indeed, we found that neither commercially available bovine ALB and TF nor ALB and TF purified by HPLC using an organic solvent as the mobile phase, could extend sperm longevity in vitro (data not shown). Although we confirmed that ALB and TF expressed in the UVJ extended sperm longevity in vitro, further studies are required to explore the above-mentioned possibility.

In our immunohistochemical analysis, we found that both ALB and TF exhibited a scattered expression pattern, indicating that only some of the cells produce ALB and TF. Because we used virgin quails in this study, we do not know if the expression levels of these proteins change after insemination. Foye-Jackson et al. (2011) investigated the expression of the avidin, avidin-related protein 2, and progesterone receptor genes in the UVJ of turkey hens, and demonstrated that the expression levels of all three genes increased after artificial insemination. Das et al. (2006) also found that expression of TGFB and its receptor were upregulated after insemination. These findings indicate that the SST gene expression pattern may be altered in the presence of resident sperm. Although we did not perform the relevant experiments, it is possible that the expression of ALB and TF may also increase in the presence of sperm in the SST.

In conclusion, we found that two proteins, ALB and TF, were expressed in the UVJ of laying quail and that these proteins had the capacity to extend sperm viability in vitro. A system to minimize ROS levels may be active in SSTs because ROS levels were efficiently lowered by the L-lactic acid-mediated arrest of sperm respiration, and putative antioxidant proteins such as ALB and TF may eliminate the generated ROS. We expect that ROS removal is one of the most important factors in sperm maintenance in SSTs. Gene expression profiling in SSTs by RNA sequencing analysis would provide new insights into the mechanisms of longterm sperm storage in avian SSTs.

\section{Acknowledgments}

This work was supported by a Grant-in-Aid for Scientific Research (B) (General) (17H03902 to TS) and a Grant-inAid for Challenging Exploratory Research (16K15022 to
TS). The authors are grateful to Mr. P. K. Sarkar for his technical assistance.

\section{Conflicts of Interest}

The authors declare no conflict of interest.

\section{References}

Bakst MR. Anatomical basis of sperm-storage in the avian oviduct. Scanning Microscopy, 1: 1257. 1987.

Bakst MR and Akuffo V. Alkaline phosphatase reactivity in the vagina and uterovaginal junction sperm-storage tubules of turkeys in egg production: Implications for sperm storage. British Poultry Science, 48: 515-518. 2007.

Bakst MR and Bauchan G. Apical blebs on sperm storage tubule epithelial cell microvilli: Their release and interaction with resident sperm in the turkey hen oviduct. Theriogenology, 83: 1438-1444. 2015.

Birkhead TR and Møller AP. Numbers and size of sperm storage tubules and the duration of sperm storage in birds: a comparative study. Biological Journal of the Linnean Society, 45: 363-372. 1992.

Bobr LW, Lorenz FW and Ogasawara FX. Distribution of spermatozoa in the oviduct and fertility in domestic birds. I. Residence sites of spermatozoa in fowl oviducts. Journal of Reproduction and Fertility, 8: 39-47. 1964.

Das SC, Isobe N, Nishibori M and Yoshimura Y. Expression of transforming growth factor- $\beta$ isoforms and their receptors in utero-vaginal junction of hen oviduct in presence or absence of resident sperm with reference to sperm storage. Reproduction, 132: 781-790. 2006.

Fanali G, Di Masi A, Trezza V, Marino M, Fasano M and Ascenzi P. Human serum albumin: From bench to bedside. Molecular Aspects of Medicine, 33: 209-290. 2012.

Foye-Jackson OT, Long JA, Bakst MR, Blomberg LA, Akuffo VG, Silva MV, Guthrie HD and McMurtry JP. Oviductal expression of avidin, avidin-related protein-2, and progesterone receptor in turkey hens in relation to sperm storage: effects of oviduct tissue type, sperm presence, and turkey line. Poultry Science, 90: 1539-1547. 2011.

Ganz T. Iron and infection. International Journal of Hematology, 107: 7-15. 2018.

Holm L, Ridderstråle Y and Knutsson PG. Localisation of carbonic anhydrase in the sperm storing regions of the domestic hen oviduct. Acta Anatomica, 156: 253-260. 1996.

Huang A, Isobe N, Obitsu $\mathrm{T}$ and Yoshimura Y. Expression of lipases and lipid receptors in sperm storage tubules and possible role of fatty acids in sperm survival in the hen oviduct. Theriogenology, 85: 1334-1342. 2016.

Ibrahim HR, Haraguchi T and Aoki T. Ovotransferrin is a redoxdependent autoprocessing protein incorporating four consensus self-cleaving motifs flanking the two kringles. Biochimica et Biophysica Acta - General Subjects, 1760: 347-355. 2006.

Ito T, Yoshizaki N, Tokumoto T, Ono H, Yoshimura T, Tsukada A, Kansaku N and Sasanami T. Progesterone is a sperm-releasing factor from the sperm-storage tubules in birds. Endocrinology, 152: 3952-3962. 2011.

Kuroki M and Mori M. Binding of spermatozoa to the perivitelline layer in the presence of a protease inhibitor. Poultry Science, 76: 748-752. 1997.

Kuscuoglu D, Janciauskiene S, Hamesch K, Haybaeck J, Trautwein $\mathrm{C}$ and Strnad P. Liver - master and servant of serum proteome. 
Journal of Hepatology, 69: 512-524. 2018.

Laemmli UK. Cleavage of Structural Proteins during the assembly of the head of bacteriophage T4. Nature, 227: 680-685. 1970.

Ma B, Zhang K, Hendrie C, Liang C, Li M, Doherty-Kirby A and Lajoie G. PEAKS: Powerful software for peptide de novo sequencing by tandem mass spectrometry. Rapid Communications in Mass Spectrometry, 17: 2337-2342. 2003.

Matsudaira P. Sequence from picomole quantities of proteins electroblotted onto polyvinylidene difluoride membranes. Journal of Biological Chemistry, 262: 10035-10038. 1987.

Matsuzaki M, Mizushima S, Hiyama G, Hirohashi N, Shiba K, Inaba K, Suzuki T, Dohra H, Ohnishi T, Sato Y, Kohsaka T, Ichikawa Y, Atsumi Y, Yoshimura T and Sasanami T. Lactic acid is a sperm motility inactivation factor in the sperm storage tubules. Scientific Reports, 5: 1-12. 2015.

Perkins DN, Pappin DJC, Creasy DM and Cottrell JS. Probability- based protein identification by searching sequence databases using mass spectrometry data. Electrophoresis, 20: 3551-3567. 1999.

Roche M, Rondeau P, Singh NR, Tarnus E and Bourdon E. The antioxidant properties of serum albumin. FEBS letters, 582: 1783-1787. 2008

Sasanami T, Pan J, Doi Y, Hisada M, Kohsaka T, Toriyama M and Mori M. Secretion of egg envelope protein ZPC after Cterminal proteolytic processing in quail granulosa cells. European Journal of Biochemistry, 269: 2223-2231. 2002.

Wheeler NC and Andrews FN. The influence of season on semen production in the domestic fowl. Poultry Science, 22: 361367. 1943.

Zaniboni L and Bakst MR. Localization of aquaporins in the sperm storage tubules in the turkey oviduct. Poultry Science, 83: 1209-1212. 2004. 